\title{
Container freight rates and the role of surcharges
}

\author{
,Brian Slack ${ }^{\mathrm{A}^{*}}$, Elisabeth Gouvernal ${ }^{\mathrm{B}}$ \\ ${ }^{\mathrm{a} C}$ Concordia University, Montreal Canada \\ ${ }^{\mathrm{b}}$ Research Director, SPLOTT, Institut National de Recherche sur les \\ transports et leur Securité , Noisy-le-Sec, France \\ "Corresponding author address: Department of Geography, Planning and Environment, \\ Concordia University, Montreal H3G 1M8, Canada slack@alcor.concordia.ca
}


Container freight rates and the role of surcharges

\begin{abstract}
This paper demonstrates that the structure of ocean container freight rates has become more complex. A growing number of surcharges are being imposed by the carriers on their customers, surcharges that are not only adding significant extra costs but are highly variable over time. These elements are examined based on a data set on export rates from ports on the Northern European Range that have been compiled from a major global carrier. The paper compares the surcharges to the base rates and discusses some of the implications for shippers who face increasing uncertainty in planning supply chains. Some of the issues for academic research on freight rates is also examined and points to the need to clearly identify what is included in the freight rate data employed. In addition, questions are raised concerning the suitability of many of the variables traditionally used to explain or predict freight rates.
\end{abstract}

Key Words: Freight rates; surcharges; container shipping

\title{
1 Introduction
}

Freight rates are a component of trade costs. Because shipping accounts for the greatest share of international trade, ocean rates help shape the patterns of international trade, even if they are a small part of cost of trade especially for manufactured products. Since 2007 years rates have fluctuated considerably, reflecting in part the decline in global trade and but also the growth in container shipping capacity (Slack 2010). In a companion paper 
(Gouvernal and Slack 2011) the trajectory of ocean freights rates between 2007 and 2009 are examined revealing significant regional differences in the degree of variation in the rates.

Not only have the regional pattern of freight rates become more diverse, but their structure has become more complex over the years. The shipping lines provide customers with quotations for base rates. In some markets, such as East Asia, the base rate may actually include some surcharges, such as the Terminal Handling Costs (THC), the Bunker Adjustment Factor (BAF) and the Currency Adjustment factor (CAF) as part of an 'all-in' rate. In the case of North America the 'all-in' rate includes land transport costs to the final destination under carrier haulage terms. In other markets these costs are charged separately from base rates. Increasingly, however, other surcharges are being added, whose scope, magnitude and temporal validity are highly differentiated, and whose numbers are increasing. The total freight rate charged to the customer, therefore, is now much higher than the simple base rate. The scale of surcharges is indicated in Figure 1. As will be explained later, there are markets where the surcharges account for more than $100 \%$ and indicate that base rates were in fact negative. The surcharges are determined by a wide range of factors, some specific to the ports of loading 
or discharge, others to general economic factors beyond the control of the shipping lines or the customer

Insert Figure 1 about here

The objective of this paper is to analyse liner shipping freight rates, and in particular, the role of surcharges. In this regard it is much broader than a number of recent papers that have focused on the BAF rate alone (Wang et al (2010); Notteboom and Verniminen (2009); Notteboom and Cariou (2009); and Cariou and Wolff (2006). It is demonstrated here that the surcharges bear little relation to the basic ocean shipping rates themselves, and are subject to increasingly frequent adjustments. This instability and the differential application of surcharges are adding a new dimension to the economics and geography of ocean shipping.

\section{Container freight rates}

Container rates are quoted as the price per box. The rate employed in container shipments, Freight All Kinds (FAK), is not theoretically a function of what is in the container, so that in container shipping tarification is not related to the product being transported, as in some other trades. Such FAK 
tariffs hide a complex reality: the rates vary by customer even for the same destination, frequently determined by the importance of the customer to the shipping line and the total volumes being shipped for this destination. This reality makes it extremely difficult to generalize with any degree of precision about how rates are structured spatially.

One of the widely available freight rate sources is published annually by Containerisation International which provides rates every quarter for the major trade lanes (see Fig 2) and reveals the variability of rates over time. However, the rates are based on averages, thus hiding the significant variations between customers and different destinations on the same trade route, and some rates include some surcharges, others do not.

\section{Insert Figure 2 about here}

Within the shipping lines, their agents who sell space on ships use a tariff grid for each port of call that is differentiated according to the type of container, 20ft, $40 \mathrm{ft}$, refrigerated etc. These grids were used during the period when the conferences were in force, since the rates were supposed to 
be charged according to agreements among conference members. Despite the disappearance of the conferences in October 2008, these grids have remained in place, with each carrier establishing its own rate structure.

These grids represent a sort of reference point. However, there has always been a great deal of latitude in dealing with large-volume customers, for whom a separate grid is set. These major accounts are typically shippers, made up of major industrial enterprises, major importers, exporters, distributors, and freight forwarders. The special grids differ for each of these clients, because their freight-slot purchases are different. The rates offered to the forwarders are revised usually every quarter, which allows the carriers to adjust the rates in response to market conditions. In fact the rates may be adjusted during the contract period, but only in cases where the rates are lowered. For the company whose rates we employ increases are incorporated in the new tariff grid established every three months, from January to March, from April to June, from July to September, and from October to December. Within the rate grids for forwarders there are various classes, based on volumes, with the very largest forwarders being allocated personalised special rates. For the shippers, however, rates are fixed for twelve month periods, typically. Terms of volume commitment exist only in 
American contracts, but penalties are not imposed for lower performance. It is only when the US contracts come up for renewal that volume discounts may be adjusted lower where previous performance levels were not met.

\section{Data sources for this study}

We focus on export rates from ports on the European Northern Range. The freight rates employed in this study were provided by one large container shipping line. The rates used are those charged to some of the largest forwarders. We were fortunate to work with a commercial agent of the shipping line who deals directly with these clients, and who conducts negotiations on a daily basis with these firms. The agent has an excellent knowledge of market conditions. While the rates accorded to these major customers may be lower by $10-25 \%$ than the grid of rates charged to other customers, the size of the forwarders and their importance in European trades means that they account for a very large percentage of traffic carried by the carrier. In addition, the fact we are dealing with the same type of client ensures that variations in rates are not due to the quality of the client. It ensures a high degree of consistency in the rates between the reporting periods. The rates were collected for the month of June. Because rates vary 
throughout the year it was decided to select the rates for one month. June was chosen for the reason that it is considered to represent a period exhibiting an average volume of traffic, in between the slow period of the early spring, and before the traffic peaks of the fall. An advantage of using rates directly from a carrier is that it is possible to breakdown the freight rates, the surcharges and the THC that for example are sometimes grouped together in the CI data. The only destinations where this breakdown is not possible are those in North America, since the quotations are "all in" rates, which for a long time have been based on carrier haulage and include land transport rates from the ports of entry to the locations of the customer. Although we obtained rates for both imports and exports, in this paper we focus on the exports because we have a complete set of surcharges.

Data on 35 port destinations from Northern Europe range were obtained. The rates and surcharges are quoted in US dollars or euros depending on the destination. In order to ensure consistency we converted the US dollar rates into euros, based on the exchange rate for June 2009.

In the following statistical analyses we employed data for all 35 ports. To facilitate regional comparisons in graphs we grouped ports into 14 market areas, and with one exception, taking the value of the port with the highest rate quoted. The only exception is China, where we excluded the inland port 
of Wuhan that consistently had the highest rates because it is served by second party feeder. In 12 of the markets there was no difference in rates between ports, the exceptions were the Middle East and the Eastern Mediterranean.

\section{Base rates}

Export rates from Northern Range ports for a 40 foot box to different markets vary considerably (see Figure 3 ). The graph reveals the remarkable case of negative rates for certain ports. This is because the rates quoted for these destinations, which were positive, included the THC, BAF and CAF surcharges, which we removed to ensure comparability across the data set.

Insert Figure 3 about here

Figure 3 reveals a number of apparent inconsistencies: a) rates to China, Korea, Japan and Singapore are negative; b) rates to East Asia and South Asia are much lower than many closer markets; c) rates to the eastern Mediterranean are high, despite the proximity; c) East Africa rates are the highest, despite the market being closer than Australia; and, d) that rates to West Coast South America are nearly double those to the East Coast of the same continent. 
These observations suggest that distance is not a factor in explaining freight rates. When base rates are correlated with distance an inverse and statistically insignificant coefficient of -0.321 is obtained. This goes against the findings of much recent research, where several authors using quantitative analysis (Wilsmeier and Hoffman 2008; Mico and Perez 2002; Limao and Venables 2000), conclude that distance is a determinant of freight rates since it is a surrogate for time at sea and thus influences variable costs such as labour and fuel. Our result supports the finding of a recent report (OECD 2008) that criticized physical distance as a good determinant of trade and that relative distance might be more appropriate, especially time.

As indicated in Fig 1, the base rates represent only a proportion of the total charges paid by shippers. The carriers add surcharges that in several markets account for a very significant portion of total rates. Given the importance of surcharges, it is important to examine their individual features and characteristics before examining again the relationships between rates and possible explanatory variables.

\section{The surcharges}


The carriers are applying a growing list of surcharges. Some have been in effect for many years, others are being introduced as new costs are being encountered which are then passed on directly to the customer. Here we examine their features and the amounts of additional charges they represent.

\subsection{Terminal Handling Costs (THC)}

This type of surcharge had been imposed by the conferences to reflect part of the container handling costs in the port terminals (Gouvernal 1997). Because the handling charges are fixed under the terms of contracts between each shipping line and the terminal operators, the surcharge was not prone to temporal fluctuations. However, under the conferences differences between ports and even for different destinations in the same port were recognized (Gouvernal et al 1997). For example, up until September 2008, the THC per forty foot container (FEU) for Le Havre was €123.33, and for Antwerp $€ 111.33$ for the same conference carrier. Two sets of THC are charged, one for the port of loading, the other for the port of discharge. The data set used in this study includes only the THC for the ports of loading. 
The policy makers who framed the EU legislation removing the anti-trust exemption from the conferences believed that surcharges and rates would be reduced (Benini and Bermin 2006). As far as surcharges, such as THCs, are concerned this has not happened. The October 2008 THC rate for Le Havre, rose immediately to $€ 160$ per FEU. One mitigating factor was that the carriers now included the ISPS surcharge, levied separately under the conference regime, into the new THC at Le Havre. However, as the previous ISPS surcharge was $€ 9.50$ per FEU, the new THC represented a significant increase in the rate charged to customers. In the case of Antwerp the THC rose to $€ 155$ but the ISPS surcharge of $€ 9$ remained in place.

Further increases in THCs have not occurred, however. The rates in Le Havre and Antwerp, for example, have remained constant at the new level established in October 2008. These rates apply to all trade lanes, which represents the only major change, apart from the increase in the rate, in the THC since the demise of the conferences. As will be demonstrated below this sets the THC surcharge as distinct from the others, that have experienced considerable volatility over time and are differentially applied according to the particular trade lane. 


\subsection{Bunker Adjustment Factor (BAF)}

BAF charges were introduced by the conferences in 1974 as a result of the oil shock. It was argued that wild swings in bunker rates could not be accounted for in base freight rates. Thus a system of surcharges was introduced to cover the costs of bunker when the price rose above a certain level. The BAF was calculated upon independent indices published in the Marine Oil Bunker Market Report and by Cockett Marine Oil Ltd (Cariou and Wolff 2006). Over the years its calculation changed from one based as a percentage of the index, calculated on a 90 day average and valid for at least three months, to a lump sum, based on a monthly calculation.

There has been research into the actual link between bunker prices and the BAF. Cariou and Wolff (2006) found a statistical relation between the trend in the average bunker price and the $\mathrm{BAF}$, but that the $\mathrm{BAF}$ over-reacts to upward and downward movements in the bunker prices. A report for the European Shippers Council ( Meyrick 2008) and an academic study by Notteboom and Cariou (2010) reveal that there are important divergences between the bunker price and the $\mathrm{BAF}$, and that the discrepancies vary significantly between some trade lanes. Thus, high differences between the 
BAF and bunker prices were noted for Africa, Latin and South America and North America, while the differences were less pronounced for the Far East and Oceania (Notteboom and Cariou 2010 where the competition is greater.

In this paper we focus on two aspects of the BAF: the regional differences in the surcharge, and its degree of temporal volatility.

\subsubsection{Regional differences}

If the BAF is assumed to be imposed to recover the extra costs of fuel, it could be presumed that longer services require more fuel than short haul routes, and thus there should be some relation between distance and BAF surcharges for the same period of time. The correlation disproves this, since the result is a non-significant and positive correlation of 0.2328 . As shown in Figure 4 there is a clustering of BAF charges in June 2009 around $€ 400$ applied to all destinations in the Far East, regardless of the distance. On the other hand exports to West Coast South America incurred BAF charges more than double those of the Far East, yet the distance is nearly half.

Insert Figure 4 about here 
Significant regional differences become clear when the rates are standardized by distance. Many markets cluster around $.025 € / \mathrm{km}$, including China, Korea, Japan, Australia, Mexico, Middle East, Philippines, and Indonesia. On the other hand East Africa $(.035 € / \mathrm{km})$, ECSA $(.045 € / \mathrm{km})$, East Mediterranean $(.040 € / \mathrm{km})$, and WCSA $(.074 € / \mathrm{km})$ reveal much higher rates. There is a strong theoretical relationship between fuel consumption per TEU carried and ship size. Scale economies, that favour large vessels, reduce rates of fuel consumption per slot. It might be expected therefore that vessel size would have an inverse relationship with the BAF. This is borne out when the BAF is correlated with size of largest ship, which produces a statistically significant negative coefficient of -.6788 .

\subsubsection{Temporal variability}

Bunker prices have risen significantly since January 2005, peaking in January 2008. As a result the carriers increased their BAF rates. The evidence compiled by Notteboom and Cariou (2010) suggest that the increases have been larger than the growth of bunker prices. The suggestion is that the carriers have been using $\mathrm{BAF}$ rates to generate more income.

In addition, there has been greater frequency of adjustments. Whereas before BAF rates changed every couple of months, over the last three years 
the fluctuations have become more frequent, with monthly fixings being the rule rather than the exception, even in the most recent period when average bunker prices have become less volatile. We have compiled the BAF rates for a larger set of markets for which we have freight rate data for the period April 2009 to December 2009. They reveal a general increase in rates that peaked in October, but that no two months had the same BAF rates (see Figure 5).

Insert Figure 5 about here

The degree of change was most pronounced in the markets with the highest initial BAF rates (see Figure 6). Thus French Guyana and WCSA experienced the greatest increases, while the Baltic and North America revealed the least proportional change. ECSA and Australia had very similar profiles and almost identical surcharges. No explanations have been found to account for the regional and temporal differences, which again suggest a degree of arbitrariness in their determination and conception.

Insert Figure 6 about here 


\subsection{Currency Adjustment Factor (CAF)}

Freight rates from Europe are quoted in a particular currency. For some markets the quotations are in euros in others in US dollars. The US dollar rates apply to destinations in the Eastern Mediterranean, the Middle East, South Asia, the Far East, Mexico, Australasia, North America, and East Africa. Over the last three years the value of the euros compared to the US dollar has fluctuated considerably, with the dollar falling below the original rate set when the euro was introduced in 2002 This variability has meant that the carriers have seen their receipts for containers charged in US dollar rates decline or vary from day to day. In order to compensate, a CAF charge is levied. For the period April - December 2009 the CAF increased every month, from an addition to the base rate of $6.66 \%$ in April, to $12.72 \%$ in December. These monthly adjustments represented a differential rate despite the consistent level of CAF because the monthly base rates to which they were applied differed according to the market. For example the June CAF of $7.87 \%$ represented an additional charge per container of 22 for Saudi Arabia or the Arab Emirates, but $€ 128$ per container for East Africa. 


\subsection{Other surcharges}

The THC, BAF and CAF rates apply very generally throughout the global shipping system. Over the years additional surcharges have been introduced to account for specific costs the carriers pass on to customers. In many cases these additional surcharges apply to one port only, but others are levied on several markets. There is also a wide spread variation in the size of the surcharge. However, the tendency is for these additional surcharges to proliferate in type and application, and a dozen or so are routinely identified in every month's summary grid of costs.

An overview of these surcharges with examples of their application is provided in Table 1.

Insert Table 1 about here

In common with the other surcharges, it is evident that these additional surcharges vary considerably in amount, spatial coverage and duration. Several are seasonal, such as the winter surcharge in the Baltic and peak 
season in India. On the other hand, others tend to be applied for long periods of time, such as canal surcharges, logistical imbalance and heavy lift . There are a number of incongruities. For example Australian shipments from Northern Europe are levied the Aden Gulf surcharge but not the passage surcharge for the Suez Canal.

\section{Total freight charges}

The full rates paid by customers in 2009 bear no relation to the base rates discussed above. These full rates are calculated from the base rates plus the surcharges added by the carrier to its customers (see Figure 7).

Insert Figure 7 about here

The results indicate that surcharges account for more than $50 \%$ of the total freight charged to customers in 9 of the 14 markets(see. figure 1). It is no surprise that the surcharges represent the major part of rates for East Asia in 2009 , since the theoretical base rates were negative. In only three markets do surcharges account for less than one third the total rates: Eastern 
Mediterranean (28\%), Australia (31\%) and Mexico (32\%). These three markets are at the opposite extremes of the geographical spectrum and are quite distinct in character.

\section{Analysis and Discussion}

A number of broad issues arise out of the above examination of surcharges. First, the scale of the surcharges is considerable, representing in most markets a very significant addition to base rates. It could be argued that 2009 is an atypical year, one in which the world economic crisis was deepest and that ocean freight rates fell proportionately to surcharges because of the lack of traffic volumes. We suggest that this was not entirely the case. The BAF rates in 2008, for example, when the conference system was still in place stood at US\$1440 per FEU for Europe-Far East in September (Notteboom and Cariou 2010), compared with US\$281 in June 2009. The high BAF rates of 2008 presumably resulted in surcharges representing an even higher proportion of total costs than in 2009. Given the history of volatility in container freight rates (see Figure 2) which year is typical? 
Second, there is considerable geographical variation in the application of surcharges. With the exception of THC in the ports of loading and the CAF, surcharge values are applied unequally in different markets. When the BAF rates are standardized by distance, for example, the difference between different markets is as much as $300 \%$. Other surcharges are market or portspecific, such as congestion or peak season. As a result surcharges must be considered in a disaggregate fashion, on a case by case basis rather than generally. This observation implies also that because surcharges represent a significant share of the total charges being billed customers, trying to explain freight rates using most of the macro economic variables used in many studies such as OECD (2008) are unlikely to be successful.

Third, the surcharges introduce a great deal of temporal uncertainty in container shipping. Customers may have obtained a fixed set of base rates for periods between three months and one year, but every month they are presented with a range of not inconsequential surcharges. During the period under study only the THC rate remained unchanged. The other increases were not uniform across all markets, for example the proportional change in the BAF rate in 2009 varied from $35 \%$ to $70 \%$ (see Table 6), a greater price differential than between the main bunkering ports. This temporal volatility 
in surcharges places a great deal of pressure on shippers, since they are unable to plan their supply chain costs for periods ahead longer than one month for FOB contracts.

Fourth, the suspicions that surcharges represent a revenue grab by the carriers and are not justified by actual conditions. Shippers and their trade organizations, especially the shippers' councils, have been vociferous in opposing surcharges. The BAF, in particular has drawn fire. The shippers argue that the BAF is a disguised rate increase that does not truly reflect actual fuel cost increases, especially now that the carriers are deploying ever larger and more fuel efficient ships. The European Shippers Council commissioned a study by an Australian consulting company to investigate whether the BAF rate increases being levied by the conferences matched the actual increases in bunker fuel prices. The study (Meyrick 2008) examined two conference routes: Europe-Far East and Europe -North Atlantic. In the report Meyrick concluded that the North Atlantic BAF rate for March 2008 was seriously overcharging customers. It estimated the BAF should have been US\$185 per TEU, whereas the conference was charging US\$607 per TEU. The discrepancy for the Far East BAF charged was less, but still appeared to indicate the carriers were overcharging. The consultant's 
estimate for the BAF was US\$385, while the actual rate charged was US\$456. The overall conclusion was that the carriers were involved in revenue generation in applying the BAF.

Other surcharges have been opposed by individual shippers' councils in different parts of the world. Recent examples include Kenya (vessel delay surcharge at Mombasa), Hong Kong (THC and BAF at Hong Kong), Asia (congestion surcharges at various Asian ports), and US (reefer surcharge). The Asia Shippers Council has stated "There are more surcharges and higher surcharges....no other industry has quite as many". (quoted in Containerisation International On Line 2, November 2009). Unlike BAF, however, there has been no comprehensive examination of surcharges and how justified they are in the context of the actual costs to the carriers or the risks involved.

Here, we cannot confirm or deny these claims with any degree of precision. However, there are a number of elements suggesting that surcharges may be covering more than actual increases in the particular costs to the shipping lines. For example, the BAF increases in 2009 varied by a wide margin for different markets. As indicated, some of this differentiation is accounted for 
by the deployment of larger ships on the services with lower percentage increases, but that factor cannot account for it all. In addition, it is noteworthy that the total surcharges for Far East markets accounted for a much higher proportion of export base costs than elsewhere, the very market where import rates fell the most during the economic crisis and where the import base rates were negative in theory.

We have already suggested that distance is not a good indicator of base rates and BAF. We developed several measures to test the relationship of these determinants and the 2009 base freight data. For distance, the values were taken from Lloyds Shipping Atlas. Two measures of trade activity were applied. Q2 imports in US dollars for 2009 for each of the markets were taken from The United Nations Monthly Bulletin of Statistics Online. This is at best a very crude surrogate since it includes imports of all kinds from countries around the world, including bulk products such as oil. The other variable was 2009 container traffic by country, obtained from Containerisation International Yearbook (2010). Finally, we included size of largest vessel employed on the trade between Europe and each region in 2009 as an indicator of the scale economies of vessels. This too is an imperfect surrogate. Average vessel size was difficult to measure because 
many separate ship services frequently involve multiple port calls in different markets.

No significant relationships are revealed for two of the variables when correlated with total rates (see Table 1). For example, distance, which in the Wilsmeier and Hoffman (2008) study is correlated highly with freight rates, here produces a statistically insignificant and inverse coefficient of -.19. One of the surrogates for market size, q2 imports is similarly statistically insignificant. The other measure of market, TEU traffic for the year, produces a statistically significant negative correlation with rates, indicating that rates, as suggested by economic theory, are responsive to some degree to market size. The variable producing the highest association with rates is that of the size of the largest vessel serving the different markets. Given the imperfect nature of the surrogates, care must be taken in interpreting these results (see Table 2 .

Insert Table 2 about here

The academic literature (Stopford 2009) suggests that freight rates are fixed by the market and that they should theoretically at least reflect in part the 
costs borne by the carriers. In reality rate determination is more complicated. The shipping companies are concerned with managing their service networks and calculate the cost per slot as a basis upon which to determine whether it should enter a particular service. Calculating the slot cost enables the carriers to determine the commercial viability of a service in a given market situation. The slot cost will reflect the size of vessel the company has at its disposal, the speed and voyage times involved, and the time spent in the ports of call. In this way the rotation time of each string can be estimated, the port costs assessed, and any canal charges determined. This permits a total slot cost for each service to be calculated.

Possessing this indicator, the company can determine what will be the returns for each container, based on the difference between the box cost and the freight rate. Thus for the carriers the slot cost is an essential tool for the management of shipping services.

Empirical research has demonstrated the significant differences between slot costs based on vessel size. Gouvernal (1997) revealed that the slot cost for a service Europe-West Africa was \$2,178, a service that employed 1500TEU vessels, compared with $\$ 1,883$ for a Europe - East Asia service using 3,500 TEU ships, despite the significantly longer voyage time for the latter. More 
recently, Stopford (2009) has calculated that the slot cost for a round trip of 14,000 miles could vary between $\$ 648$ and $\$ 360$, depending on the size of the ship $(1,200$ TEUs or 11,000 TEUs). Comparable differences were obtained by Notteboom (2004) and Cullinane and Khanna (2000).

The differences based on scale economies reveals important differences in the competitivity of different shipping lines whose fleet profiles differ. The slot cost advantages of very large ships helps understand why so many carriers committed themselves to an unprecedented placement of orders for new ships in 2006-8, most of which were of the largest size. The massive order book was a contributing factor to the collapse of freight rates in 20082009.

\section{Conclusions}

This paper demonstrates that the nature of freight rates has become more complex. A growing number of surcharges are being applied to all trade routes. This has a number of consequences for shippers. First, shippers find that the base rates quoted and negotiated with the carriers do not reflect the total set of charges levied. Second, the surcharges are changed with considerable frequency, a situation that adds uncertainty 
to shippers who are seeking to plan their supply chains. Third, there is growing evidence that many of the surcharges are not transparent and do not reflect the actual costs incurred by the carriers. This is seen by many in the shipping and ports industry to be a revenue grab.

There are consequences too for academic research. The spread between base rates and surcharges revealed in this paper, suggests that the academic community must use extreme caution in employing 'ocean freight rates'. There must be much more clarity in defining the composition of rates employed in research. Because many of the surcharges are applied unequally between trades, it brings into question the appropriateness of many explanatory variables traditionally used in quantitative analyses.

We have suggested the importance of the slot cost for the carriers in fixing their tariffs, and the way this consideration places ever more emphasis on vessel scale economies. However, it highlights a weakness of this analysis, in that we explore rates and surcharges on one segment of a service only, the exports from Northern European ports. Carriers, however, base their slot costs on an entire service, and fix their freight rates for each leg with reference to the total. In our companion paper Gouvernal and Slack 2011) we explore this issue in a preliminary 


\section{fashion. However, to shed further light on the issue there is a need to \\ identify the surcharges on the import European trades and to compare \\ them with those examined in this paper.}

\section{References}

Benini,F. and Bermin C., 2006. The commission proposes to repeal the Liner Conference Block Exemption. Competition Policy Newsletter, Spring, 43-50.

Cariou,P. and Wolff, F-C., 2006. An Analysis of Bunker Adjustment Factors and Freight Rates in the Europe/Far-East Market (2000-2005). Maritime Economics and Logistics 8, 187-201.

Containerisation International Yearbook 2010.

Containerisation Online,2010 (www.ci-online.co.uk ) viewed September 72010

Cullinane, K. and Khanna, M., 2000. Economies of Scale in large containerships: optimal size and geographical implications. Journal of Transport Geography (8) 181-195.

Gouvernal,E., Guilbault, M. and Rizet, C., 1997 Politiques de transport et compétitivité., Paris :Hermès.

Gouvernal, E., 1997_Le monde redessiné par les coûts de la ligne régulière in Politiques de transport maritime et portuaire et compétitivité. Paris :Hermès.

Gouvernal, E. and Slack, B., 2011. Container freight rates and the mapping of economic space. Paper under review.

Limao, N. and Venebales, A.J., 2001 Infrastructure, geographical disadvantage, transport costs and trade. The World Bank Economic Review 15(3), 451-479.

Meyrick and Associates, 2008. Review of BAFs - Transatlantic and Europe-Far East trades Brussels:European Shippers Council, May.

Mico, A.and Perez, N. 2002. Determinants of maritime transport costs. Working Paper, No 441.

Notteboom,T. 2004. Container Shipping and Ports:an overview. Review of Network Economics 3 (2), 86-106. 
Notteboom, T. and Cariou., 2009. Fuel surcharge practices of container shipping lines: is it about cost recovery or revenue-making?. Paper presented at the annual conference of Maritime Economists. Lisbon.

Notteboom T. and Vernimmen B., 2009. The effect of high fuel costs on liner service configuration in container shiping. Journal of Transport Geography 17, 325-337.

OECD,2008. Clarifying Trade Costs in Maritime Transport. TAD/TC/WP(2008)/REV2. Paris:OECD.

Slack, B. (2010). Battening down the hatches: how should maritime industries weather the economic tsunami?" Research in Transport Economics, 27, 4-9.

Stopford, M., 2009. Maritime Economics. London: Lloyds Press.

UNstats. Total Imports and Exports. Table 35. Monthly Bulletin in Statistics, UNstats.un.org $\backslash$ unsa $\backslash$ mbs. Consulted July 2010.

Wang,D-H, Chen, C-C, and Lai, C-S., 2010. The rationale behind effects of Bunker Adjusment Factors. Journal of Transport Geography, In Press.

Wilmsmieir, G. and Hoffman, J., 2008. Liner Shipping Connectivity and Port Infrastructure as Determinants of Freight Rates in the Caribbean Maritime Economics and Logistics, 10, 130-151. 


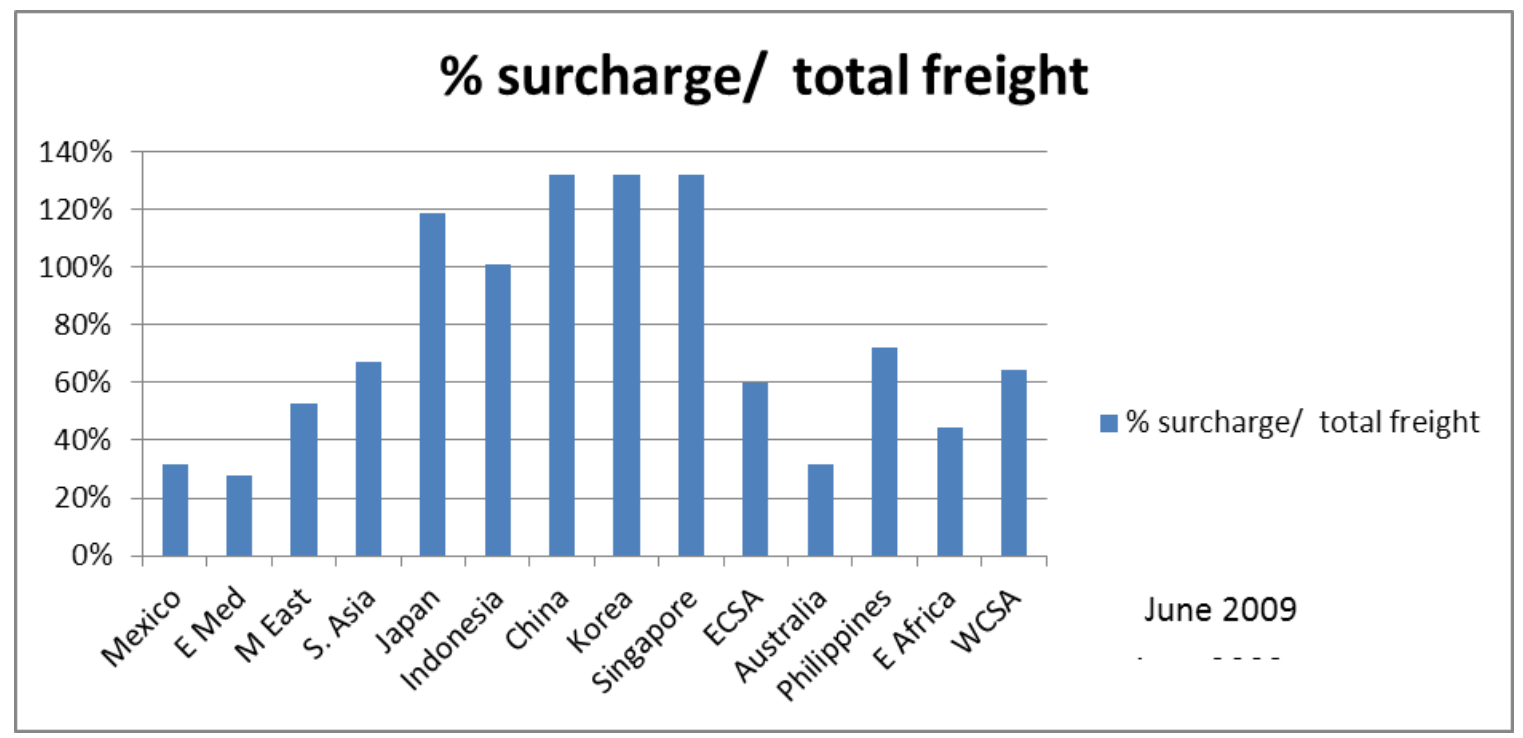

Figure 1 Surcharges as a proportion of total rates from the European Northern Range, June 2009. 


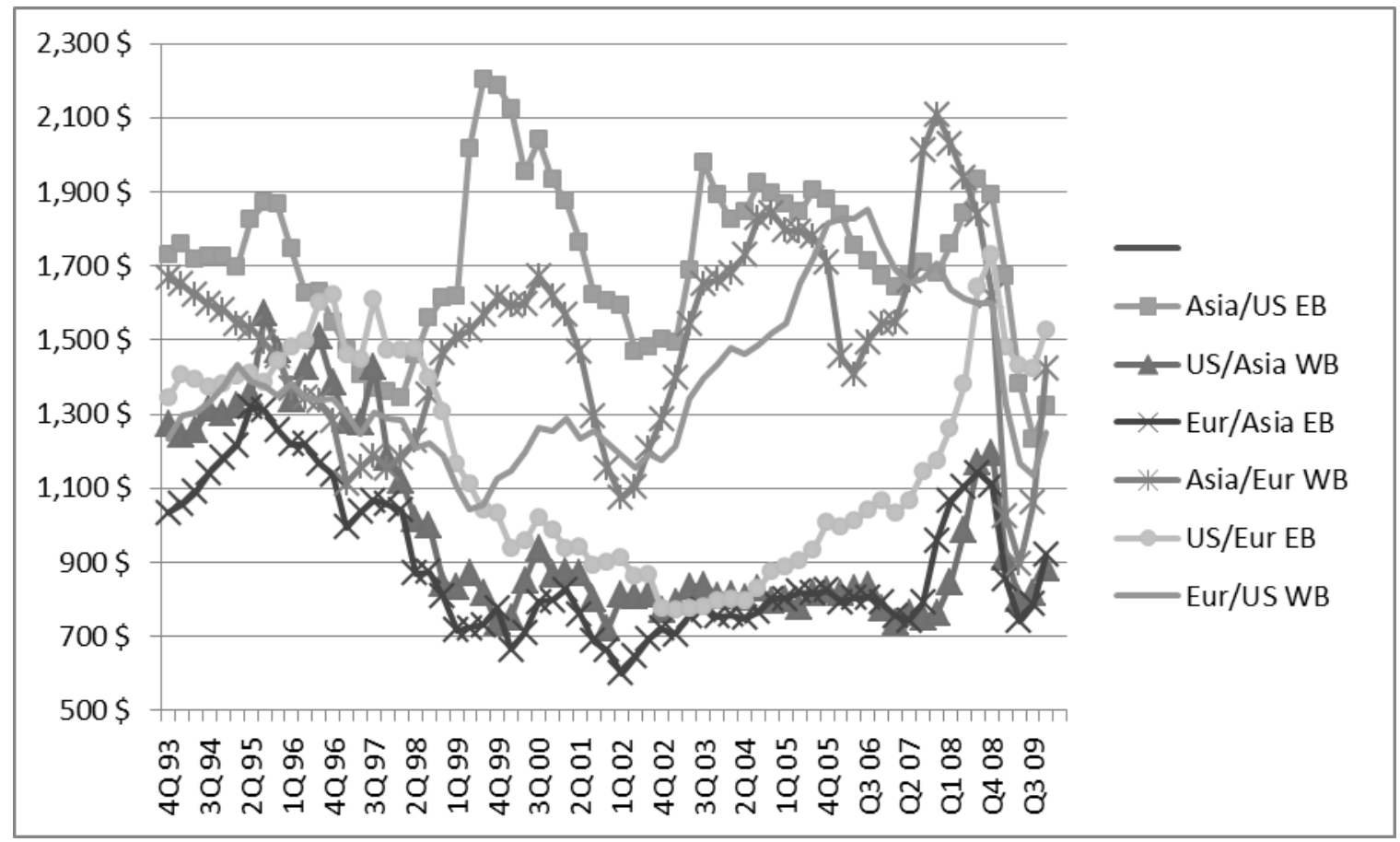

Figure 2 Container Freight Rates, 1993-2009 (www.ci-online.co.uk) viewed September 72010 


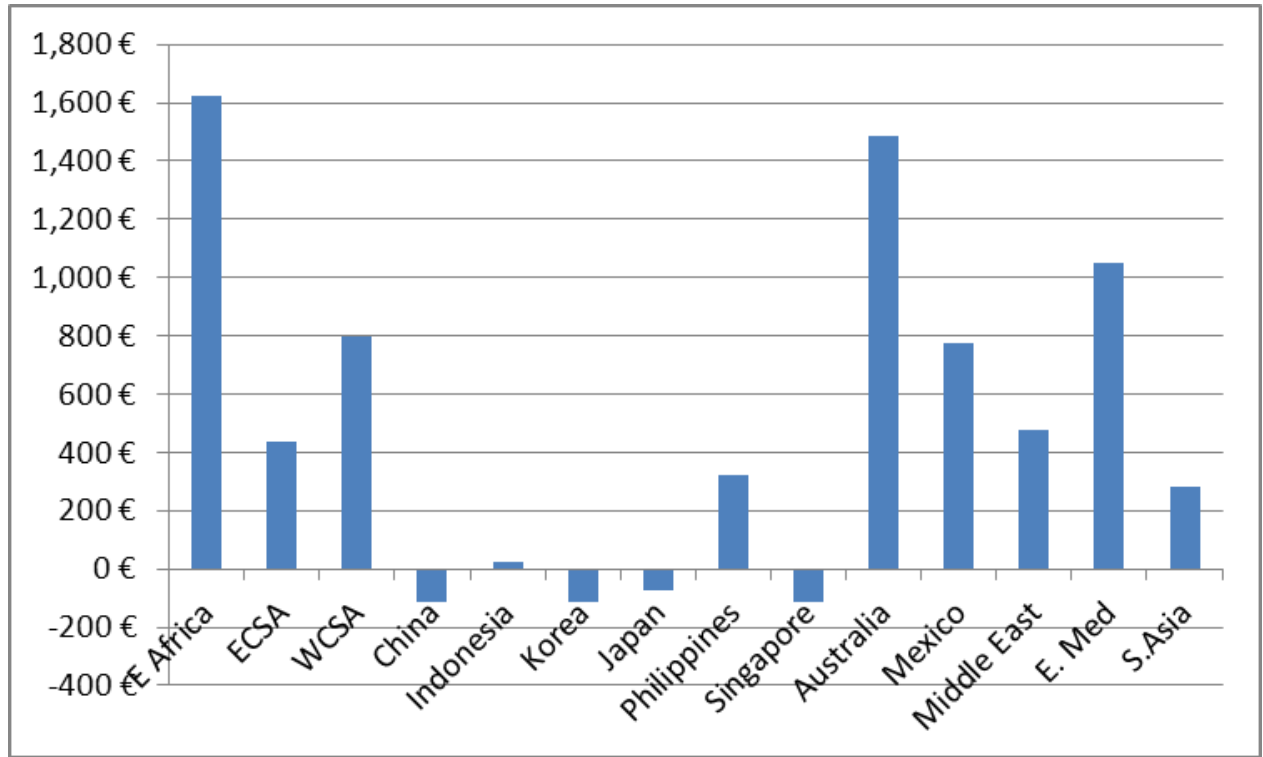

Figure 3 Base Freight rates June 2009 


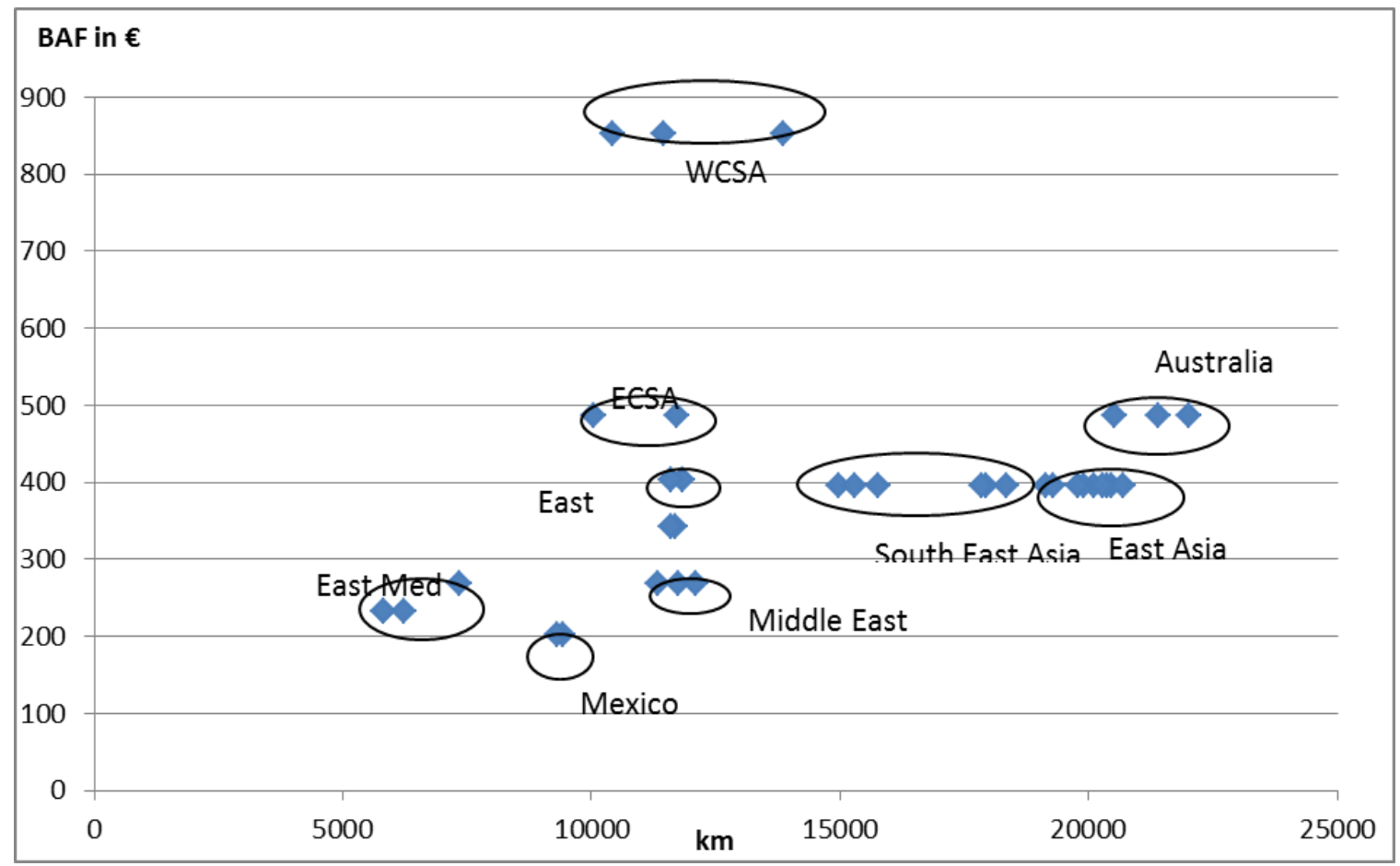

Figure 4 Bunker Adjustment Factor and Distance 


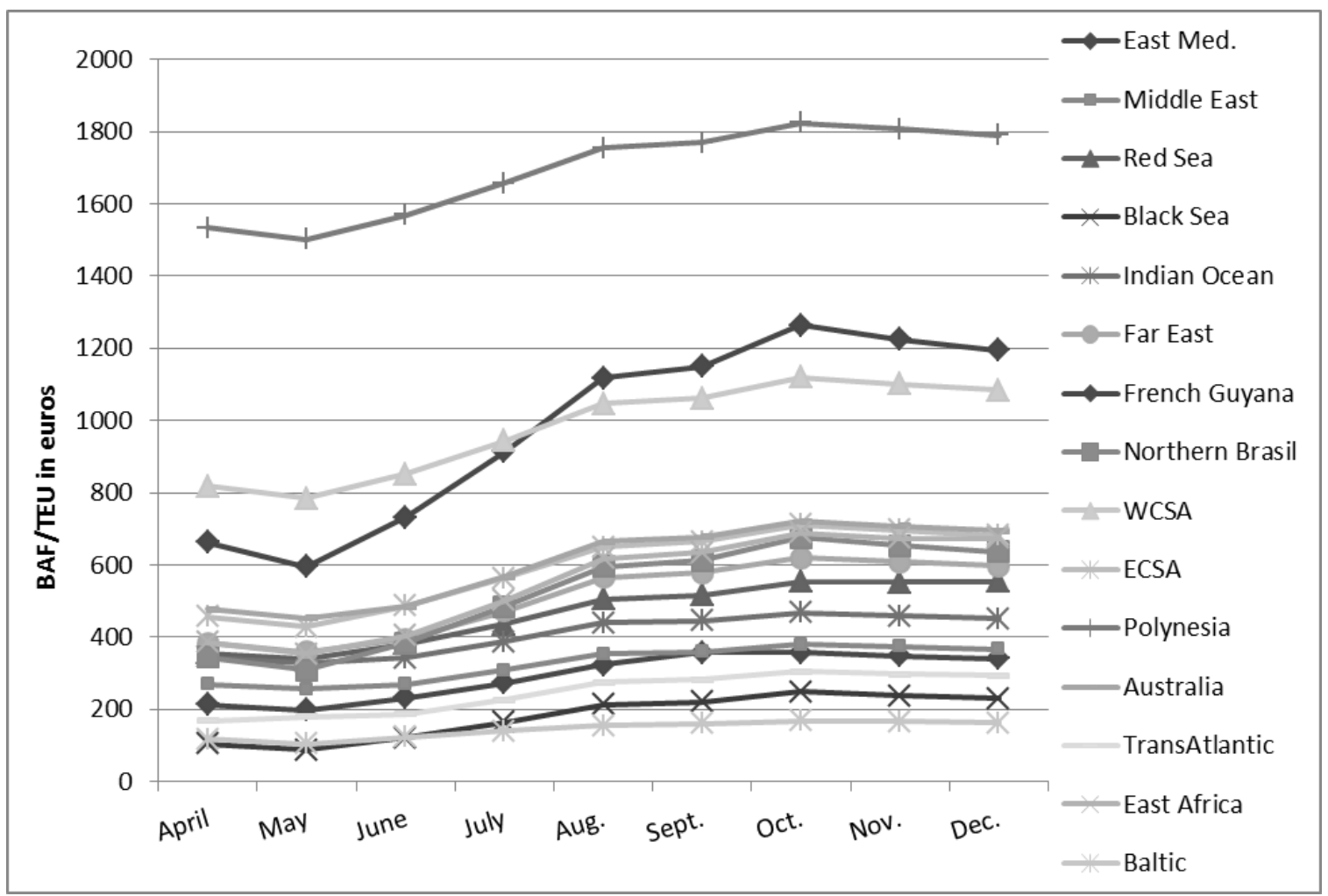

Figure 5 Monthly variations in the BAF, April-December 2009 


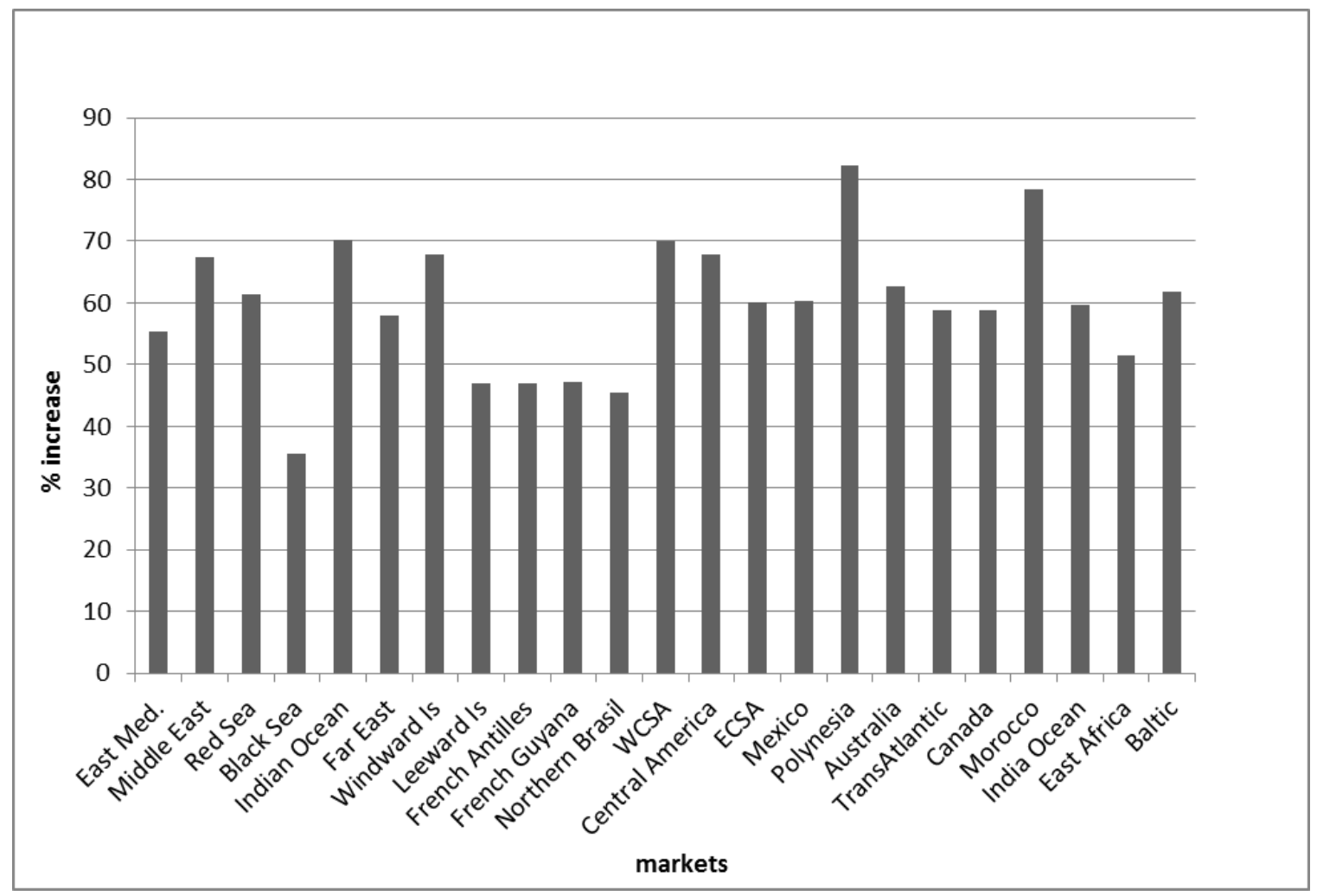

Figure 6 Percentage increase in BAF rates May-October 2009 


\begin{tabular}{|c|c|c|}
\hline Surcharge & levy/teu & example \\
\hline Congestion & $€ 40$ & Callao \\
\hline War risk & $€ 15$ & Syria \\
\hline Aden gulf & $\$ 23.00$ & Middle East \\
\hline Suez Canal transit & $\$ 9.00$ & Middle East \\
\hline Panama Canal transit & $\$ 175.00$ & WCSA \\
\hline Chassis Pool & $\$ 60.00$ & USEC \\
\hline Logistical imbalance & $€ 15$ & Morocco \\
\hline Peak season & $\$ 150$ & India \\
\hline Piracy & $€ 20$ & East Africa \\
\hline Water level & $\$ 150.00$ & Montreal \\
\hline Heavy weight & $\begin{array}{l}\$ 250 / \text { teu if over } 10 \text { metric } \\
\text { tons }\end{array}$ & Australia \\
\hline Winter surcharge & $€ 50$ & Baltic \\
\hline
\end{tabular}




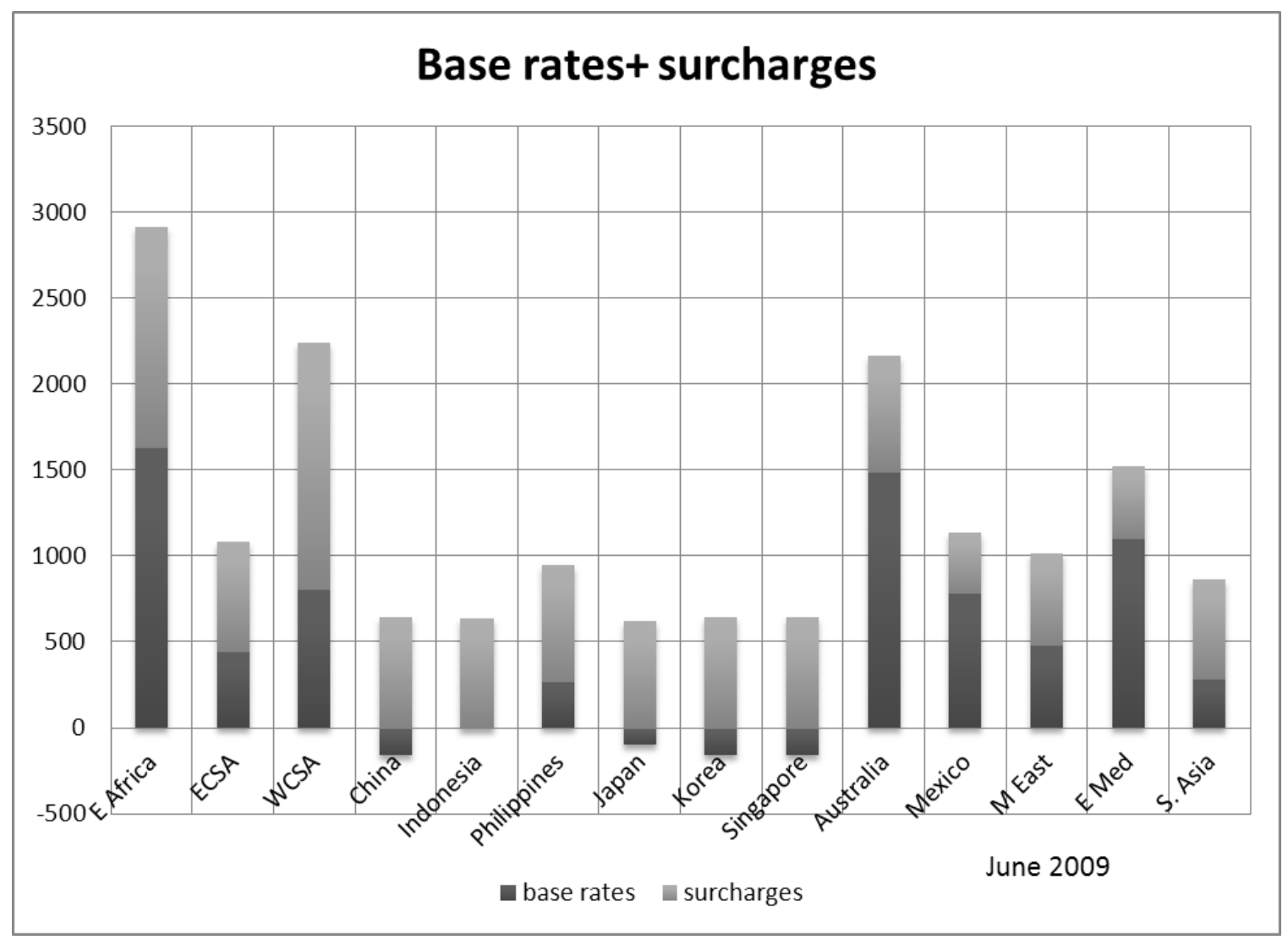

Figure 7 Total Freight Rates, base rates plus surcharges 


$\begin{array}{lrrrr} & \begin{array}{l}\text { Size of } \\ \text { vessel }\end{array} & \text { distance } & \begin{array}{l}\text { q2 2009 } \\ \text { imports }\end{array} & \text { TEU total } \\ \text { Total } & & & & \\ \text { rates } & -0.618 & -0.188 & -0.418 & -0.545\end{array}$

TABLE 1 Correlations with total rates 